\title{
MANAJEMEN USAHA IKAN FUFU DI DESA TAMBALA KAMPUNG BARU KECAMATAN TOMBARIRI KABUPATEN MINAHASA PROVINSI SULAWESI UTARA
}

\author{
Rian Rinaldi'; Nurdin Jusuf2; Grace.0.Tambani² \\ 1)Mahasiswa Fakultas Perikanan dan IImu Kelautan Universitas Sam Ratulangi Manado \\ 2)Staff Pengajar Fakultas Perikanan dan IImu Kelautan Universitas Sam Ratulangi Manado \\ Koresponden email : rianrinaldi907@gmail.com
}

\begin{abstract}
Indonesian fisheries resources regarding food in the fisheries sector have great potential, this is an important factor in supporting national development.

This study aims to determine the management of "fufu" fish business in Tambala Kampung Baru Village, Tombariri District, Minahasa Regency, North Sulawesi Province, namely the system of processing and marketing of "fufu" fish.

The research method is descriptive in order to describe the characteristics of a situation. Data retrieval is done by census method, where there are 19 "fufu" fish business owners, then data is collected on all business objects. Primary data was taken through direct interviews using a questionnaire to "fufu" fish business owners and secondary data is the data of viewers in this study.

"Fufu" fish production in Tambala Kampung Baru Village is adjusted to the acquisition of capital obtained by the business owner, where in 10 respondents it can be seen that the availability of raw materials in the production process varies from $300 \mathrm{~kg}$ to $500 \mathrm{~kg}$. Marketing plans have been established after business planning.

The economic aspect of the "fufu" fish business can provide good profit. This is because operational costs are relatively low, when compared to other businesses, producer marketing is not difficult, and the average processing process is carried out for 7 days.
\end{abstract}

Keywords: management, "fufu" fish business, tambala village

\section{Abstrak}

Sumberdaya perikanan Indonesia menyangkut bahan pangan dalam bidang perikanan memiliki potensi besar, hal ini merupakan faktor penting dalam menunjang pembangunan bangsa.

Penelitian ini bertujuan untuk mengetahui manajemen usaha ikan "fufu" di Desa Tambala Kampung Baru Kecamatan Tombariri Kabupaten Minahasa Propinsi Sulawesi Utara yaitu sistem pengolahan dan pemasaran ikan "fufu".

Metode penelitian bersifat deskriptif dengan tujuan menguraikan sifat-sifat dari suatu keadaan. Pengambilan data dilakukan dengan metode sensus, dimana terdapat 19 pemilik usaha ikan "fufu", kemudian dilakukan pengambilan data terhadap keseluruhan objek usaha. Data primer diambil melalui wawancara secara langsung dengan menggunakan kuesioner kepada pemilik usaha ikan "fufu" dan data sekunder merupakan data-data penujang dalam penelitian ini.

Produksi ikan "fufu" di Desa Tambala Kampung Baru disesuaikan dengan perolehan modal yang diperoleh pemilik usaha, dimana dalam 10 responden dapat dilihat ketersedian bahan baku dalam proses produksi bervariasi antara $300 \mathrm{~kg}$ sampai dengan $500 \mathrm{~kg}$. Rencanah pemasaran sudah ditetapkan setelah adanya perencanan usaha.

Segi ekonomis usaha ikan "fufu" dapat memberikan keutungan yang baik. Hal ini disebabkan biaya oprasionalnya relatif rendah, bila dibandingkan dengan usaha lain, produsen pemasaran tidak sulit, dan proses pengolahan ratarata dilakukan selama 7 hari.

Kata kunci: Manajemen, usaha ikan "fufu", Desa Tambala

\section{PENDAHULUAN}

\section{Sumberdaya}

perikanan

Indonesia menyangkut bahan pangan dalam bidang perikanan memiliki potensi besar, hal ini merupakan faktor penting dalam menunjang pembangunan bangsa. Keperluan akan sumberdaya tersebut dirasakan semakin lama semakin meningkat selaras dengan meningkatnya perkembangan penduduk dan pembangunan diseluruh sektor kehidupan. Oleh sebab itu, pemanfaatan sumberdaya perairan harus diusahakan seoptimal mungkin tanpa mengganggu kelestariannya (Kalla, 2008).

Pendekatan manajemen banyak dipakai karena dapat menjalankan dan mengandalkan usaha dengan berpegang pada prinsip memperoleh laba maksimal dengan usaha yang seminimal mungkin. Pada hakekatnya fungsi manajemen 
adalah mengatur dan menggerakkan orang-orang serta sumberdaya lainnya untuk bekerja sesuai dengan harapan yang ingin dicapai (Bahari, 1997).

\section{METODE PENELITIAN}

.Dasar penelitian yang digunakan adalah survey, yaitu penelitian yang dilakukan dengan cara mengumpulkan, menyidik dan menafsirkan data secara umum sebagaimana adanya di lapangan yang mencakup satu satuan wilayah tertentu (Daniel, 2003).

Sugiyono (2001), menyatakan bahwa teknik sampel random sampling adalah teknik pengambilan sampel dari anggota populasi yang dilakukan secara acak tanpa memperhatikan strata yang ada dalam populasi itu dalam penelitian ini yang dijadikan responden berjumlah 10 pengusaha dari 19 pengusaha ikan "fufu" di Desa Tambala Kampung Baru.

Data yang dikumpulkan terdiri dari data primer dan data sekunder. Data primer diperoleh dengan menggunakan teknik pengisian daftar pertanyan atau kuesoner yang sudah disiapkan untuk diwawancarai serta diobservasi langsung kepada pemilik usaha ikan "fufu". Data sekunder adalah data yang diperoleh dari data statistik yang ada di kantor Desa Tabala Kampung Baru serta lembaga-lembaga atau instansi lain yang ada kaitannya dengan objek penelitian.

Analisis data dilakukan dengan menggunakan metode analisis deskriptif kualitatif dan analisis deskriptif kuantitatif.

\section{HASIL DAN PEMBAHASAN}

Desa Tambala merupakan desa pemekaran dari Desa Sarani Matani pada tahun 1985 persiapan pembetukan Desa Tambala pada Okteber tahun 1986 secara defenitif maka bentuk desa baru yang kemudian diberi nama Desa
Tambala dari pada tahun 1986 Desa Tambala sudah ada permukiman penduduk yang disatukan dalam 1 lingkungan dengan 7 jaga, Adapun Desa Tambala dikhususkan pemerintah untuk pengungsian orang Sanger yang ada di Elu. Pada waktu dimekarkan Desa Tambala hanya terdiri dari 2 (dua) jaga tapi sekarang sudah menjadi 7 jaga. Nama Desa Tambala diambil dari kata sungai yang ada di Desa Tambala, kata Tambala berasal dari kata Tombala. Terbagi dari dua kata Tou Wala yang artinya orang bersinar atau bercahaya.

\section{Keadaan Penduduk Desa Tambala}

Kehidupan penduduk Desa Tambala umumnya memiliki kehidupan yang sama seperti penduduk desa pada umumnya. Penduduk Desa Tambala selain berasal dari suku bangsa Minahasa, ada juga yang berasal dari Gorontalo, Jawa, Sanger, Talaud dan ada juga dari Makasar. Suku yang ada di Desa Tambala bisa dikatakan berimbang. Penduduk pendatang yang ada di Desa Tambala untuk bertujuan mencari nafkah, tapi ada juga yang bertujuan tinggal dan menjadi masyarakat tetap Desa Tambala.

Berdasarkan data sensus penduduk, dimana jumlah penduduk yang ada di Desa Tambala yaitu 2.551 jiwa yang tersebar di tujuh jaga yang terdiri dari laki-laki 1.334 jiwa dan perempuan 1.217 jiwa dengan jumlah KK 683. Dari data tersebut dapat dilihat bahwa jumlah laki-laki lebih banyak dibandingkan dengan perempuan.

Meskipun penduduk Desa Tambala terdiri dari latar belakang yang berbeda-beda, namun dalam kehidupan sehari-hari terlihat adanya kerja sama yang baik, memiliki rasa toleransi antara sesama anggota masyarakat dan rasa tolong menolong yang besar. Di Desa 
Tambala sendiri dulunya sempat ada kegiatan mapalus, tapi sangat disayangkan kegiatan tersebut hanya sampai pada tahun 90-an dan akhirnya diberhentikan dengan alasan wilayah Desa Tambala berada di daerah pantai sedangkan untuk menjalankan kegiatan mapalus ada baiknya jika wilayah tersebut berada di daerah pegunungan sehingga mata pencarian bergantung hasil laut dan hasil perkebunan. Tapi saat ini di Desa Tambala ada juga organisasi sosial yang berada dibawah pimpinan pemerintah yaitu: Rukun Kasih, Rukun Pinasungkulan, PKK dan ada juga rukun-rukun keluarga lainnya. Bentuk-bentuk kerja sama seperti ini masih terpelihara dengan baik karena masing-masing anggota masyarakat beranggapan bahwa mereka juga akan mengalami peristiwa duka maupun suka yang nantinya akan membutuhkan bantuan.

Berdasarkan data hasil Kantor Desa Tambala penduduk Tambala menurut data hasil sensus sebagian besar tidak tamat sekolah dasar dengan jumlah 576 atau $22.5 \%$ dan ada juga yang menenpuh pendidikan samapai dengan strata 2 berjumalah 3 orang atau $0,11 \%$.

\section{Manajemen Produksi Ikan "Fufu" Perencanaan Produksi}

Realisasi setiap usaha membutukan suatu manajemen yang baik, sehingga penggunaan sumberdaya dapat dilakukan secara efektif dan efisien terhadap hasil atau profit yang memuaskan. Oleh karena itu, untuk mencapai tujuan yang diinginkan dalam suatau usaha diperlukan suatau perencanan yang tepat. Perencanan yang dimaksud adalah kegiatan suatu usaha yang akan dikerjakan dengan mengumpulkan peralatan dan sarana yang ada dalam hal ini perencanan merupakan jembatan menuju kepada sasaran yang ingin dicapai dalam pekerjaan tersebut.

Pada umumnya usaha ikan "fufu" di Desa Tambala Kampung Baru masih dalam home industry atau usaha rumah tanggah dengan manajemen yang digunakan masih dapat dikatakan tergolong sederhana, usaha tersebut dipimpin oleh pemilik usaha, yang juga merencanakan segala kegiatan dalam usaha tersebut.

Produksi disesuaikan dengan perolehan modal yang diperoleh pemilik usaha, dimana dalam 10 responden dapat dilihat ketersedian bahan baku dalam proses produksi bervariasi antara $300 \mathrm{~kg}$ sampai dengan $500 \mathrm{~kg}$. Rencana pemasaran sudah ditetapkan setelah adanya perencanan usaha.

Ikan cakalang yang diterima oleh pemilik usaha, terlebih dahulu pekerjaan yang harus dipersiapkan adalah kebutuhan-kebutuhan yang berhubungan dengan kegiatan pengolahan, yaitu antara lain:

1. Penyediaan bak penampung ikan,

2. Penyediaan alat pemotong ikan,

3. Penyediaan penjepit/bambu unutk mengait ikan,

4. Penyedian sabut kelapa,

5. Penyediaan keranjang guna penampungan ikan untuk pemasaran. Penyediaan kebutuhan pengolahan ini membantu para pekerja agar lebih mudah untuk melakukan pekerjaan. Maka ketersediaanyapun sudah ada di tempat pengasapan sehingga para pekerja dapat langsung melakukan proses pengolahan.

\section{Ketersediaan Bahan Baku}

Ikan merupakan hal yang sangat penting untuk diperhatikan dalam kesediaan bahan baku baik dari tingkat kualitas, kesegaran, dan tekstur dari ikan 
tersebut. Karena sifaf ikan yang muda busuk jika ditahan lebih lama, maka pemilik usaha ikan cakalang "fufu" lebih teliti dalam memilih kualitas ikan yang akan diproduksi.

Asal bahakan baku ikan yang di ambil dari pelelangan ikan yang berada jati pasar tuminting dan juga ikan yang berasal dari amurang, dan tambala dari nelayan sekitar.

\section{Proses Pengolahan Produk}

Proses pengolahan ikan asap rata-rata dilakukan 7 kali dalam sebulan oleh pemilik usaha, sehari banyaknya ikan yang diolah adalah $300-500 \mathrm{~kg}$. Peralatan dan bahan yang digunakan seperti rak dari besi penahan ikan saat pengasapan, bambu, pisau, dan sabut kelapa. Setiap hari pengasapan dilakukan dengan berbagai variasi ada yang 200 ekor ikan, dan ada juga 100 ekor ikan. Jika 200 ekor ikan akan menjadi 400 jepit ikan "fufu" dan jika 100 ekor ikan akan menjadi 200 jepit ikan asap. Berat ikan dapat dirata-ratakan ukurannya, untuk yang ukuran kecil panjang $12 \mathrm{~cm}$ memiliki berat $500 \mathrm{gr}-1$ $\mathrm{kg}$, sedangkan untuk ukuran besar panjang $18 \mathrm{~cm}$ memiliki berat 2-4 kg. Proses pengolahan dilakukan sebanyak tiga kali dalam sehari, tapi ada juga yang melakukan satu kali proses pengolahan dalam sehari. Adapun cara pengolahan sebagai berikut:

1. Ikan cakalang dibersihkan dengan mengeluarkan sisik, insang, mata tulang dan jeroannya,

2. Daging dibelah dua dan dijepit dengan kerangka bambu,

3. Daging ikan diolah dengan dibaluri pewarna makanan,

4. Daging ikan diletakan di atas rak pengasapan,

5. Sabut kelapa diatur merata di bawah rak pengasapan, kemudian daging siap untuk dilakukan pengasapan,
6. Proses pengasapan dilakukan selama 2 jam supaya panas harus merata dengan keadaan api bewarna biru, hingga daging ikan "fufu" kelihatan matang,

7. Setelah dilakukan proses pendinginan selama 30 menit kemudian diatur untuk dijual pada komsumen.

\section{Manajemen Pemasaran}

Rantai Pemasaran Ikan "fufu"

Pemasaran ikan "fufu" di Desa

Tambala Kampung Baru dilakukan dengan langsung dijual oleh pemilik usaha ke konsumen akhir melalui pendistribusian produknya di pasarpasar tradisonal dan supermarket. Hal ini menujukan bahwa produk tersebut sudah layâk dijual dan memiliki daya saing yang cukup.

Adapun tahap-tahap tingkat pemasaran ikan cakalang asap :

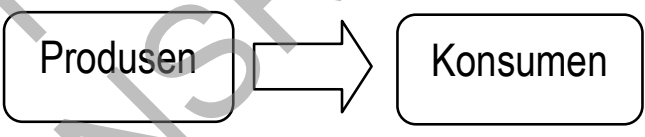

Rantai pemasaran merupakan rantai pendek. Produsen yaitu pemilik usaha ikan "fufu" langsung menjual produknya kepada konsumen. Penjualannya berbeda-beda untuk yang sekali produksi langsung menjualnya kepada konsumen.

\section{Manajemen Keuangan Usaha Ikan "Fufu"}

Segi ekonomis usaha ikan "fufu" dapat memberikan keutungan yang baik. Hal ini disebabkan biaya operasionalnya relatif rendah dan produsen pemasarannya tidak sulit, kemudian proses pengolahan rata-rata dilakukan selama 7 hari.

Segmentasi pasar ikan "fufu" di desa Tambala ditujukan memenuhi semua kalangan. Hal ini biasa dilihat dari 
pendistribusiannya dilakukan di pasarpasar tradisonal maupun supermarket. Diman produk ikan "fufu" dapat ditemukan diberbagai tempat penjualan khususnya di daerah Kota Manado seperti di samping rumah makan idaman jalan sario yang mempunyai tempat khusus penjualan ikan "fufu", pasar girian bitung, pasar bersehati, pasar segar paal dua, pasar teling tanawangko pasar wonasa, pasar karombasan dan pasar perkamil. Sedangkan untuk supermarket dapat ditemukan produknya di fiesta dan golden.

Ikan "fufu" di pasar tradisonal dan supermarket harganya berbedabeda, dimana dipasar tradisonal harga rata-rata Rp. 30.000 perjepit sedangkan disupermarket harga rata-rata Rp. 47.500 perjepit. Perbedaan harga ini dikarenakan ikan "fufu" yang disupermarket sudah dikemas dengan lebih rapi untuk menarik perhatian konsumen. Hal ini membuat segmentasi penetapan produk mempunyai daya beli kosumen relatif tinggi karena adanya unsur kerapian dan higinis di dalam pemasaran tersebut.

\section{Biaya Tetap}

Biaya tetap (fixed cost) dari usaha ikan "fufu" adalah jenis-jenis biaya selama periode kerja tetap dan tidak mengalami perubahan. Biaya tetap berupa penyusutan rumah pengasapan, parang, pisau, kerajang ikan dengan umur ekonomi 5 tahun. Rata-rata biaya penyusutan dari 10 reponden pemilik usaha ikan "fufu", yaitu Rp. 5.634 .600

Biaya Penyusutan dan Perawatan Selama 1 Tahun

\begin{tabular}{|l|r|r|r|r|}
\hline \multicolumn{1}{|c|}{ Uraian } & $\begin{array}{r}\text { Nilai Investasi } \\
\text { (Rp) }\end{array}$ & Masa Pakai & $\begin{array}{r}\text { Nilai Penyusutan } \\
\text { (Rp) }\end{array}$ & \multicolumn{1}{c|}{$\begin{array}{c}\text { Perawatan } \\
\text { (Rp) }\end{array}$} \\
\hline Rumah Pengasapan & 9.727 .000 & 5 tahun & 1.945 .400 & 500.000 \\
\hline Meja Tempat penjualan ikan & 427.000 & 5 tahun & 85.400 & 480.000 \\
\hline Rak Pengasapan & 4.918 .000 & 5 tahun & 983.600 & 300.000 \\
\hline Parang & 222.000 & 5 tahun & 44.400 & - \\
\hline Keranjang lkan & 950.000 & 5 tahun & 190.000 & - \\
\hline Pisau & 44.000 & 5 tahun & 8.800 & -100.000 \\
\hline Lampu & 250.000 & 5 tahun & 50.000 & -1.380 .000 \\
\hline Tali raffia & 275.000 & 5 tahun & 55.000 & $\mathbf{3 . 3 6 2 . 6 0 0}$ \\
\hline
\end{tabular}

Sumber Data Primer, 2018.

Perolehan biaya tetap tidak hanya diperoleh dari biaya penyusutan, kemudian ditambah dengan biaya pajak bumi dan bangunan retribusi. Hal ini dikarenakan rumah pengasapan dari usaha ikan "fufu" dikenakan pajak bumi dan bagunan (PBB) yang rata-rata pertahunnya sebesar Rp. 52.000 .

Biaya Tetap Usaha Cakalang "Fufu" Selama 1 Tahun

\begin{tabular}{|c|l|r|}
\hline No. & \multicolumn{1}{|c|}{ Uraian } & Jumlah pajak/tahun (Rp) \\
\hline 1. & Pajak bumi dan bangunan & 52.000 \\
\hline 2. & Pajak retribusi & 840.000 \\
\hline 3. & Biaya Perawatan & 1.380 .000 \\
\hline 4. & Biaya Penyusutan Jumlah & 3.362 .600 \\
\hline \multicolumn{2}{|c|}{ J.634.600 } \\
\hline
\end{tabular}

Sumber Data Primer, 2018. 


\section{Biaya Tidak Tetap}

Biaya tidak tetap (variabel cost) biaya yang berubah sepanjang proses produksi atau naik turun biaya secara bersamaan dengan volume kegiatan. Adapun rata-rata hasil analisis biaya tidak tetap 10 responden.

Biaya Tidak Tetap Usaha Ikan "fufu" selama 1 Tahun

\begin{tabular}{|c|l|r|r|r|}
\hline No & \multicolumn{1}{|c|}{ Uraian } & Jumlah & $\begin{array}{c}\text { Harga/unit } \\
\text { (Rp) }\end{array}$ & $\begin{array}{c}\text { Total Harga } \\
\text { (Rp) }\end{array}$ \\
\hline 1. & lkan (Kg) & 33.600 & 17.400 & 584.640 .000 \\
\hline 2. & Bambu (bh) & 47 & 5.700 & 267.900 \\
\hline 3. & Pewarna makanan (bh) & 252 & 5.000 & 1.260 .000 \\
\hline 4. & Sabut kelapa/drop (bh) & 240 & 150.000 & 36.000 .000 \\
\hline 5. & Tali raffia (bh) & 84 & 26.500 & 2.226 .000 \\
\hline 6. & Botol (bh) & 180 & 175 & 31.500 \\
\hline 7. & Upah Tengah KERJA & 336 & 50.000 & 16.800 .000 \\
\hline 8. & Listrik @ 12 bln & 12 & 295.000 & 3.540 .000 \\
\hline
\end{tabular}

Sumber: Data Primer, 2018.

\section{Total Biaya Produksi dan Pendapatan}

Total produksi dalam suatau usaha dapat mempengaruhi pendapatan sehingga merupakan hal yang wajar diperoleh. Dikatakan wajar karena berperan penting untuk mengukur tingkat produktivitas pada usaha yang dijalakan, apakah memperoleh hasil atau tidak.

Total Produksi dan Pendapatan Usaha Selama 1 Tahun

\begin{tabular}{|l|r|r|r|}
\hline \multicolumn{1}{|c|}{ Jenis Produk } & $\begin{array}{c}\text { Rata-rata Jumlah } \\
\text { Produksi (kg) }\end{array}$ & $\begin{array}{r}\text { Rata-rata Penjualan } \\
\text { (Rp) }\end{array}$ & $\begin{array}{c}\text { Perolehan } \\
\text { Pendapatan } \\
\text { (Rp) }\end{array}$ \\
\hline Ikan "fufu" ukuran kecil & 18.900 & 30.000 & 567.000 .000 \\
\hline Ikan "fufu" ukuran besar & 6.300 & 51.500 & 324.450 .000 \\
\hline Bakasang botol & 180 & 10.000 & 1.800 .000 \\
\hline Tulang \& hati ikan onggok & 180 & 15.000 & 2.700 .000 \\
\hline & & & 895.950 .000 \\
\hline
\end{tabular}

\section{KESIMPULAN}

Berdasarkan hasil dan pembahasan di atas maka dapat disimpulkan sebagai berikut:

1. Usaha ikan "fufu" di Desa Tambala Kampung Baru masih dalam home industry atau usaha rumah tangga, sistem manajemen yang digunakan masih dapat dikatakan tergolong sederhana, dimana usaha tersebut dipimpin oleh pemilik usaha, yang juga merencanakan segala kegiatan dalam usaha tersebut.

2. Pemilihan bahan baku meliputi tingkat kualitas, kesegaran dan tekstur ikan, agar produksi ikan cakalang "fufu" sesuai dengan selera konsumen.

3. Pemasaran ikan "fufu" di Desa Tambala Kampung Baru dilakukan dengan menjual ke konsumen akhir, baik melalui pasar-pasar tradisonal maupun supermarket.

4. Pengolahan ikan cakalang "fufu" dilakukan sebanyak satu sampai dengan tiga kali dalam sehari, tergatung jumlah bahan baku ikan cakalang. 


\section{DAFTAR PUSTAKA}

Abidin, Z. 2013. Manajemen Agrobisnis Perikanan. Jurnal. Universitas Brawijaya.

Bangun, W. 2008. Intisari Manajemen dan Motovasi. Balai Aksara. Jakarta.

Buchari, dan Zainun 2000. Manajemen dan Motivasi. Balai Aksara. Jakarta

Daniel, M. 2003. Metodologi Penelitian Sosial Ekonomi. Bumi askara. Jakarta

Kadaria. 1995. Evaluasi Proyek Analisa Ekonomi. Edisi Kedua. Universitas Indonesia. Jakarta

Kalla, M. 2008. Perikanan unggulan.PT. Ciptawidya Swara. Jakarta. Timur.

Lasut, Melinda. 2015. Sejarah Desa Tambala Kecamatan Tombariri
Nawai. 2010. Metodologi Penelitian Bidang Sosial. UGM-Press. Yogyakarta

Nikijuluw, V. 2005. Politik Ekonomi Perikanan FERACO. Jakatra

Rahardi, F.R. Kristiawati dan Nazarudin, 1993. Agribisnis Perikanan.PT. Penebar Swadaya. Jakarta.

Roni, G. 2004. Kamus Lengkap Bahasa Indonesia. Penerbit Terbit Terang. Surabaya.

Simamora, 2003. Memenangkan Pasar dengan Pemasaran Efektif dan Profitable. Penerbit PT.Gramedia Pustaka Utama. Jakarta.

Stoner, J.A.F. 1996. Manajemen.Jilid 1. Penerbit Erlanga. Jakarta. 
PS. Agrobisnis Perikanan FPIK UNSRAT

AKULTURASI

Available online :http://ejournal.unsrat.ac.id/index.php/akulturasi

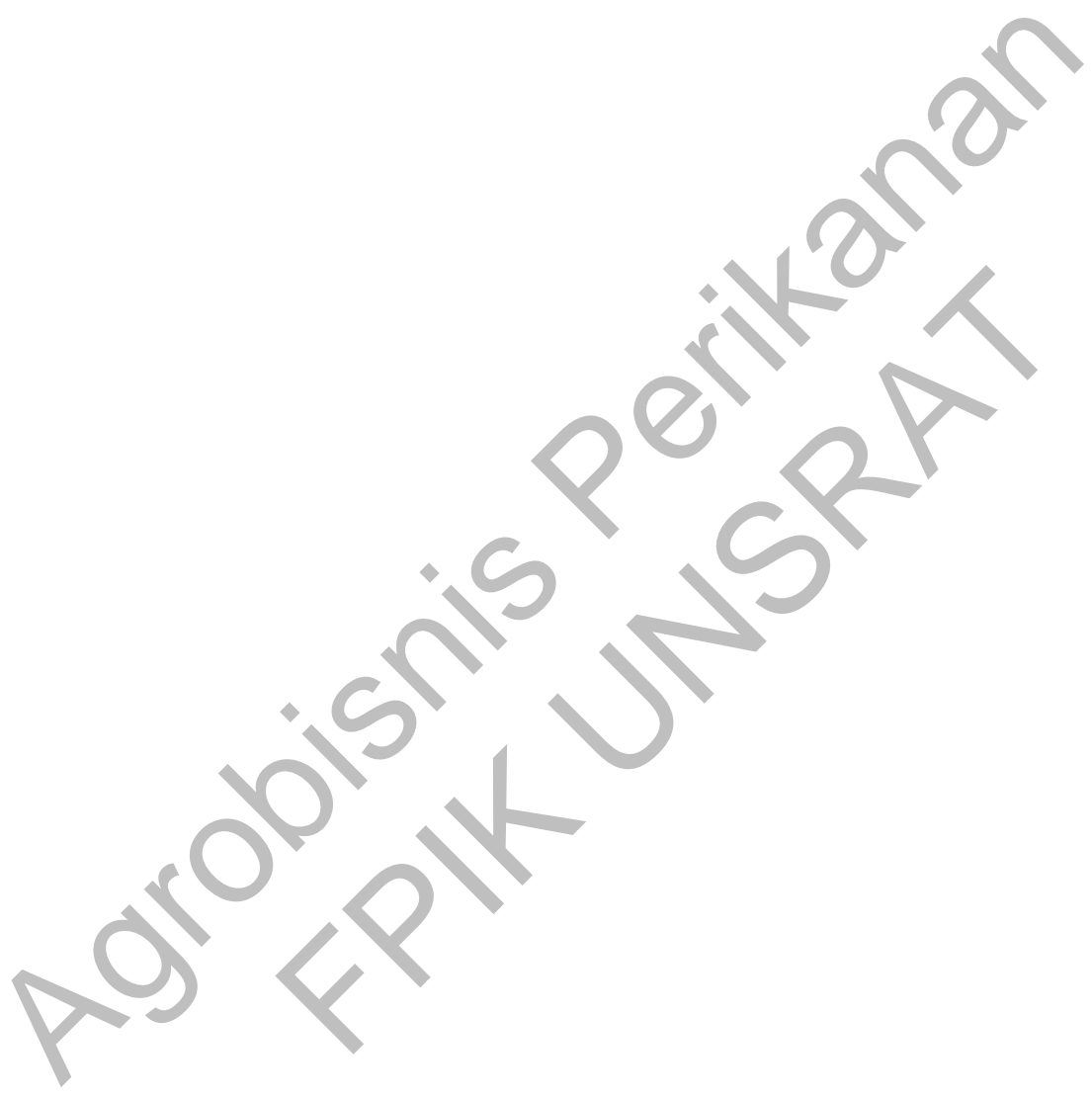

